\title{
Pea seed-borne mosaic virus: Stability and Wind-Mediated Contact Transmission in Field Pea
}

B. S. Congdon, School of Plant Biology and Institute of Agriculture, Faculty of Science, University of Western Australia, Crawley, WA 6009, Australia; B. A. Coutts, Crop Protection Branch, Department of Agriculture and Food Western Australia, Perth, WA 6983, Australia; M. Renton, School of Plant Biology and Institute of Agriculture, Faculty of Science, University of Western Australia; and R. A. C. Jones, School of Plant Biology and Institute of Agriculture, Faculty of Science, University of Western Australia, and Crop Protection Branch, Department of Agriculture and Food Western Australia

\begin{abstract}
Congdon, B. S., Coutts, B. A., Renton, M., and Jones, R. A. C. 2016. Pea seed-borne mosaic virus: stability and wind-mediated contact transmission in field pea. Plant Dis. 100:953-958.

Pea seed-borne mosaic virus (PSbMV) stability in sap and its contact transmission between field pea plants were investigated in glasshouse experiments. When infective leaf sap was kept at room temperature and inoculated to plants in the absence of abrasive, it was still highly infective after $6 \mathrm{~h}$ and low levels of infectivity remained after $30 \mathrm{~h}$. PSbMV was transmitted from infected to healthy plants by direct contact when leaves were rubbed against each other. It was also transmitted when intertwining healthy and PSbMV-infected plants were blown by a fan to simulate wind. When air was blown on plants kept at 14 to $20^{\circ} \mathrm{C}$, contact transmission of PSbMV occurred consistently and the

extent of transmission was enhanced when plants were dusted with diatomaceous earth prior to blowing. In contrast, when plants were kept at 20 to $30^{\circ} \mathrm{C}$, blowing rarely resulted in transmission. No passive contact transmission occurred when healthy and infected plants were allowed to intertwine together. This study demonstrates that PSbMV has the potential to be transmitted by contact when wind-mediated wounding occurs in the field. This may play an important role in the epidemiology of the virus in field pea crops, especially in situations where contact transmission expands initial crop infection foci before aphid arrival.
\end{abstract}

Pea seed-borne mosaic virus (PSbMV; family Potyviridae, genus Potyvirus) causes a serious disease in pea (Pisum sativum) crops worldwide. It also infects several other cool-season crop legumes, causing diseases in faba bean (Vicia faba), chickpea (Cicer arietinum), lentil (Lens culinaris), and various vetches (Vicia sp.) (Bos et al. 1988; Fletcher 1993; Makkouk et al. 2014). From the pea's original domestication centers in the Mediterranean basin and Near East, PSbMV has been disseminated worldwide by international trade in pea seed, facilitated by its seedborne nature, which gave rise to its name (Hampton and Mink 1975; Khetarpal and Maury 1987). Seed infection levels of up to $47 \%$ occur in commercial seed stocks, resulting in widespread PSbMV incidence in crops and harvested seed (e.g., Coutts et al. 2008; Latham and Jones 2001a). When pea seed with high PSbMV infection levels is sown and the subsequent crop becomes infected at high incidences at an early growth stage, substantial seed yield losses and quality defects occur (Ali and Randles 1998; Coutts et al. 2008, 2009; Latham and Jones 2001b). Sowing infected pea seed produces infected plants that act as a primary inoculum source for plant-to-plant spread by aphid vectors in a nonpersistent manner throughout the growing season (Khetarpal and Maury 1987). Aphid transmission has been considered the only form of plant-to-plant PSbMV transmission occurring in the field. However, the possibility of PSbMV spread by plant-to-plant contact has not been investigated.

Contact transmission from infected to healthy plants occurs readily with highly stable viruses that reach high titers within their host plants (Bawden 1964; Matthews 1981). This allows transmission to occur without the presence of a vector. Viruses in the genera Potexvirus (e.g., Hu et al. 1994; McKirdy et al. 1998), Carlavirus

Corresponding author: B. Congdon;

E-mail: benjamin.congdon@research.uwa.edu.au

Accepted for publication 4 December 2015.

http://dx.doi.org/10.1094/PDIS-11-15-1249-RE

(C) 2016 The American Phytopathological Society (e.g., Franc and Bantarri 2001), Sobemovirus (e.g., McKirdy et al. 1998), and Tobamovirus (e.g., Hu et al. 1994) all spread commonly by contact. Wounding of the host plant is a prerequisite for this to occur, because it allows particles of the virus to cross the leaf cuticle, penetrate the cell wall, and enter cells, in which they replicate (Bawden 1964; Matthews 1981). Such spread between infected and healthy plants in the field can occur by the transfer of infective sap from crushed, infected plant material to healthy plants on the mouthparts or hooves of livestock, farm machinery, pruning and cutting tools, and human clothes and hands (Broadbent and Fletcher 1963; Cleugh et al. 1998; Coutts and Jones 2015; Coutts et al. 2013; Franc and Bantarri 2001; Hu et al. 1994; Jensen and Gold 1955; Kamenova and Adkins 2004; McKirdy et al. 1998; Todd 1958). It can also occur by leaf abrasion due to plant-toplant contact induced by wind (Brey et al. 1988; Broadbent and Fletcher 1963; Loughnane and Murphy 1938; Sarra et al. 2004; Sill 1953).

Four members of the family Potyviridae are contact transmitted with varying levels of efficiency: (i) Zucchini yellow mosaic virus (ZYMV) in cucurbit species (Cucurbita pepo and C. maxima) (Coutts et al. 2013) and (ii) Potato virus $Y$ (PVY) in potato and tomato, both by contaminated tools, clothes, and machinery (Coutts and Jones 2015; Wintermantel 2011); (iii) Bean yellow mosaic virus in gladiolus by contaminated tools (Brierly 1962); and (iv) Wheat streak mosaic virus in wheat by wind-mediated leaf contact (Brey et al. 1988; Sill 1953). Their transmission still occurred despite the relatively lower stability and titer of members of Potyviridae compared with typical contact-transmitted viruses (Matthews 1981). Contact transmission of these Potyviridae species is usually aided by features of host plant leaf morphology (i.e., large, soft leaves or leaves with abrasive hairs, as on Cucurbita sp. and potato plants) (Coutts et al. 2013; Coutts and Jones 2015).

As mentioned above, stability is a prerequisite for a virus to be contact transmissible. In one report, PSbMV-infected sap diluted with distilled water remained infective for at least $96 \mathrm{~h}$ (Knesek et al. 1974) but further studies on the stability of PSbMV infectivity are needed, especially using undiluted sap. Additionally, PSbMV spread still occurs readily when no aphids colonize pea crops and 
when few noncolonizing migrant aphids are present (Coutts et al. 2009). This provides anecdotal evidence that contact transmission following leaf wounding by friction caused by wind may also occur. This could be enhanced by increased abrasion due to the presence of airborne dust or sand (Cleugh et al. 1998). No attention has been paid to this potentially important PSbMV transmission route. Early PSbMV spread by contact transmission before aphids arrive would expand infection foci within the crop for subsequent aphid transmission to occur later in the growing season, effectively accelerating the rate of virus spread. Therefore, there is a need to determine whether wind-mediated contact transmission occurs with PSbMV and, if so, under what conditions it might play a significant role in spreading infection in the field.

This article describes a series of glasshouse experiments undertaken to establish whether PSbMV is (i) stable in infective sap, (ii) transmitted passively from infected to healthy pea plants by intertwining, (iii) transmitted from infected to healthy pea plants by leaf rubbing, and (iv) transmitted from infected to healthy pea plants when blown by fans (simulating wind) with or without previous dusting with an abrasive.

\section{Materials and Methods}

Plants, sap inoculation, and virus isolates. Except when specified otherwise, all plants were maintained at 19 to $23^{\circ} \mathrm{C}$ in insect-proof glasshouses. For use as PSbMV culture hosts and in experiments, plants of 'Twilight' and 'Kaspa' field pea (semidwarf, semileafless type) and 'Fiord' faba bean were grown in a sand/potting mix (50: 50 blend) or potting mix, respectively. For mechanical inoculation of culture hosts and experiment infector plants, leaves from systemically PSbMV-infected plants were ground in $0.1 \mathrm{M}$ phosphate buffer, $\mathrm{pH}$ 7.2, and the infective sap was mixed with diatomaceous earth before being rubbed onto leaves. A culture of PSbMV isolate W1 obtained from infected pea in 1998 in Western Australia (Latham and Jones 2001b) was maintained by serial mechanical inoculation of infective sap to plants of pea or faba bean. Leaf samples from pea or faba bean plants infected with isolate W1 were used as the positive control in enzyme-linked immunosorbent assay (ELISA) and as inoculum for experiments. All plants were sprayed with the insecticide imidacloprid $(0.125 \mathrm{~g} /$ liter $)$ to ensure that no aphids were present.

ELISA. To test for virus infection, leaf samples were extracted $(1 \mathrm{~g}$ per $20 \mathrm{ml})$ in $\mathrm{pH} 7.4$ phosphate-buffered saline $(10 \mathrm{mM}$ potassium phosphate, $150 \mathrm{mM}$ sodium chloride, Tween 20 at $5 \mathrm{ml} /$ liter, and polyvinyl pyrrolidone at $20 \mathrm{~g} /$ liter) using a mixer mill (Retsch). Sample extracts were tested for PSbMV by double-antibody sandwich ELISA, as described by Clark and Adams (1977). The polyclonal antiserum to PSbMV used was from DSMZ. All samples were tested in duplicate wells in microtiter plates. Sap from PSbMV-infected and healthy pea or faba bean leaf samples were always included in paired wells to provide positive and negative controls, respectively. The substrate was $p$-nitrophenyl phosphate at $1.0 \mathrm{mg} / \mathrm{ml}$ in diethanolamine, $\mathrm{pH} 9.8$, at $100 \mathrm{ml} / \mathrm{liter}$. Absorbance values at $405 \mathrm{~nm}\left(\mathrm{~A}_{405}\right)$ were measured in a microplate reader (Bio-Rad Laboratories). Positive absorbance values were always at least 10 times those of the healthy sap.

Stability in sap. Five experiments were done to establish the stability of PSbMV infectivity in sap. Sap was extracted from faba bean leaves infected with isolate W1 using a leaf press. The undiluted sap extracts were allowed to dry at room temperature for nine time periods ranging from $5 \mathrm{~min}$ to $30 \mathrm{~h}$. For each time period, 2-ml aliquots of infective sap extracts were placed into individual porcelain bowls. The infective sap was left for 5 or $30 \mathrm{~min}$ or 1, 2, 3, 6, 12, 24, or $30 \mathrm{~h}$ before $2 \mathrm{ml}$ of distilled water was added. Once the sap was resuspended, it was immediately inoculated without addition of buffer or abrasive onto leaves of five faba bean plants (four leaves per plant). Five plants were left uninoculated as controls. A single newly emerged leaf was sampled from each plant 21 and 28 days after inoculation and tested individually for PSbMV by ELISA.

Transmission by leaf rubbing and passive contact. Eight glasshouse experiments with Twilight and Kaspa pea (four experiments each) were undertaken to establish whether PSbMV could spread from infected to healthy plants by (i) leaf rubbing or (ii) passively by plant intertwining. For leaf rubbing, there were 10 pots, each with one healthy and one PSbMV-infected pea plant allowed to grow and intertwine for the duration of the experiment. A leaf from a separate pea plant infected with PSbMV isolate W1 was rubbed onto the leaf surface of the healthy pea plant in such a way as to induce moderate wounding. This was performed on the upper leaf surfaces of the top six leaves of 103 -week-old healthy pea plants once a day for 3 days. For passive contact transmission, 10 pots, each containing one healthy and one infected pea plant, were allowed to grow and intertwine for the duration of the experiment with no leaf rubbing. For controls, 10 pots, each containing two intertwining healthy pea plants, were rubbed in the same way with a leaf from a separate healthy pea plant. All plants were examined for symptom development, and a single newly emerged leaf sampled from each plant 21 and 28 days after rubbing was tested individually by ELISA. A significant difference in transmission rates between the two pea cultivars was tested for using a two-tailed $Z$ test.

Simulated wind-mediated contact transmission. To investigate the impact of wind in mediating PSbMV contact transmission, oscillating fans were used to blow "wind" onto groups of healthy 3-weekold pea plants growing with 5-week-old pea plants infected with $\mathrm{PSbMV}$ isolate $\mathrm{W} 1$ (infector plant). The fans were placed $30 \mathrm{~cm}$ from the pea plants and exerted effective wind speeds of 3 to $4 \mathrm{~ms}^{-1}$, measured using an anemometer. Four types of experiments were done, with duplicates (A and B) of each type:

Experiment 1. Six pots (160 $\mathrm{mm}$ in diameter), each containing one central pea infector plant (Kaspa) with two healthy pea (Kaspa) plants (one on either side), were blown once a day for $2 \mathrm{~h}$ at a time for 12 days. An identical set of six pots was dusted with diatomaceous earth prior to each blowing, such that all leaves on each plant were covered. Another identical set of six pots was left unblown to test for passive transmission, and a further set of six pots, each containing three healthy pea plants (but no infector plant), was blown in the same way as a control. The pots were blown in groups of three without fan oscillation. The arrangement of the three pots was altered after each blow so that each pot had equal time in each position.

Experiment 2. Six pots ( $160 \mathrm{~mm}$ in diameter) containing either a pea (Twilight) or a faba bean (Fiord) infector plant with two healthy pea (Twilight) plants (one on either side) were blown once a day for $2 \mathrm{~h}$ at a time for 12 days. An identical set of six pots was left unblown to test for passive transmission, and a further set of six pots, each containing four healthy pea plants (but no infector plant), was blown in the same way as a control. The six pots in each treatment were all blown together each time with fan oscillation, and the pot arrangement was altered after each blow so that each pot had equal time in each position

Experiment 3. Six tubs ( 30 by 15 by $15 \mathrm{~cm}$ ), each containing one row of 10 healthy pea (Twilight) plants with a pea (Twilight) infector plant in the middle of the row, were blown at 2-day intervals for $1 \mathrm{~h}$ at a time over 12 days (Fig. 1). An identical set of six tubs was left unblown to test for passive transmission. Six tubs containing rows of 11 healthy pea plants without infector plants were blown in the same way as a control. The tubs were blown in groups of three at a time with fan oscillation, and the tub arrangement was altered after each blow so that each tub had equal time in each position.

Experiment 4. This was a repeat of experiment 3, except that there were five tubs per treatment and each tub was blown at 2-day intervals for $2 \mathrm{~h}$ at a time over 12 days.

In all these experiments, a single newly emerged leaf from each plant from each pot or tub was sampled 21, 28, and 35 days after the first blowing time and tested individually by ELISA.

Experiments $1 \mathrm{~A}, 1 \mathrm{~B}$, and $3 \mathrm{~A}$ were undertaken under cooler glasshouse temperatures during winter $\left(14\right.$ to $\left.20^{\circ} \mathrm{C}\right)$ while experiments 2A, 2B, 3B, 4A. and 4B were undertaken in warmer glasshouse temperatures during summer $\left(20\right.$ to $\left.30^{\circ} \mathrm{C}\right)$. In experiments $1 \mathrm{~A}, 1 \mathrm{~B}$, and $2 \mathrm{~B}$, the PSbMV titer in leaf tip samples from each infector plant in the unblown treatment was determined at the midway point of the experiment. A healthy pea plant leaf was used as a control. ELISA optical density $(\mathrm{OD})$ values $\left(\mathrm{A}_{405}\right)$ for each sample were exponentially 
transformed ( $\mathrm{e}^{\mathrm{x}}=$ "antilog ${ }_{\mathrm{e}}$ " = "inverse $\log _{\mathrm{e}}$ ") before being subjected to analysis of variance (equivalent to a $t$ test) to test for any significant difference in titer between warmer and cooler conditions. Exponential transformation was done to obtain a linear relationship between OD values and virus titer (Wilson and Jones 1993). Additionally, a one-tailed $Z$ test was used to test whether PSbMV transmission rates under warmer glasshouse conditions $\left(20\right.$ to $\left.30^{\circ} \mathrm{C}\right)$ were significantly different from those obtained under cooler glasshouse conditions (14 to $20^{\circ} \mathrm{C}$ ), and also to test whether transmission rates were higher when plants were dusted with diatomaceous earth than when the abrasive was absent (experiments 1A and 1B).

\section{Results}

Stability in sap. In 5 of 5 experiments, PSbMV-infected leaf sap remained infective for up to $6 \mathrm{~h}$, with PSbMV being detected in leaf samples in up to 5 of 5 faba bean plants (Table 1). In 2 of 5 experiments, some infectivity was still detected after 24 and $30 \mathrm{~h}$ in leaf samples ( 1 of 5 to 2 of 5 plants). Foliar symptoms developed in infected faba bean plants consisting mainly of leaf distortion and chlorosis and mild plant stunting. None of the control plants became infected.

Transmission by leaf rubbing and passive contact. In all eight experiments, transmission occurred when a PSbMV-infected pea leaf was rubbed onto leaves of healthy pea plants (Table 2 ). In four experiments, 1 of 10 to 4 of 10 plants (Kaspa) or 2 of 10 plants (Twilight) became infected. There was no significant difference in numbers of

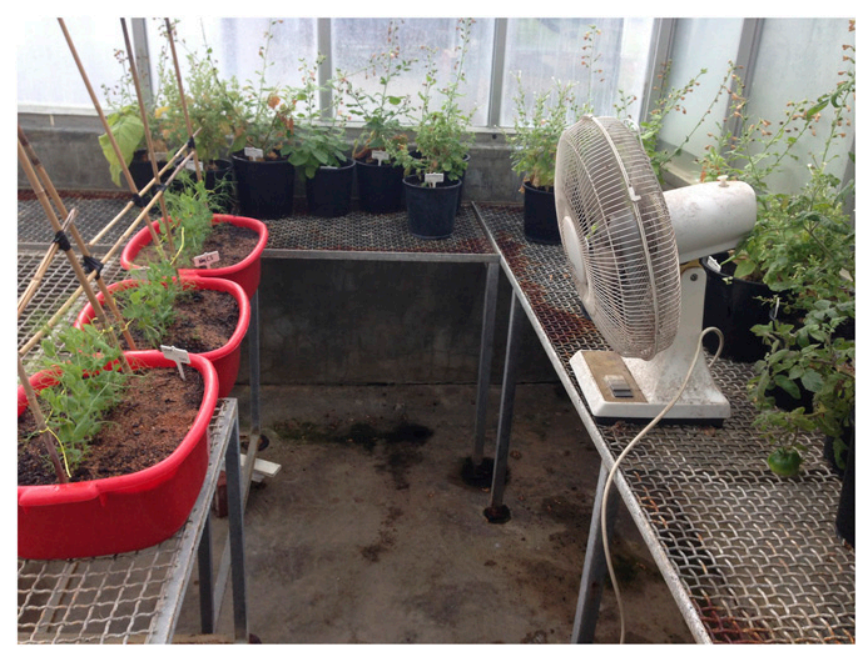

Fig. 1. Oscillating pedestal fan blowing rows of 10 field pea plants with one Pea seed-borne mosaic virus infector plant midrow within each tub (experiment $3 \mathrm{~A}$ ).

Table 1. Survival of Pea seed-borne mosaic virus (PSbMV) infectivity in sap incubated for different time periods before inoculation to plants ${ }^{\mathrm{a}}$

\begin{tabular}{lccccccccc}
\hline & \multicolumn{8}{c}{ Incubation time periods prior to inoculation } \\
\cline { 2 - 10 } Exp. & $\mathbf{5}$ $\mathbf{b i n}$ & $\mathbf{3 0} \mathbf{~}$ in & $\mathbf{1} \mathbf{~ h}$ & $\mathbf{2} \mathbf{~ h}$ & $\mathbf{3 ~ h}$ & $\mathbf{6 ~ h}$ & $\mathbf{1 2} \mathbf{~ h}$ & $\mathbf{2 4} \mathbf{~ h}$ & $\mathbf{3 0} \mathbf{~ h}$ \\
\hline 1 & $2 / 5$ & $4 / 5$ & $2 / 5$ & $4 / 5$ & $5 / 5$ & $1 / 5$ & - & $0 / 5$ & - \\
2 & $5 / 5$ & $2 / 5$ & $4 / 5$ & $5 / 5$ & $3 / 5$ & $4 / 5$ & - & $2 / 5$ & - \\
3 & $5 / 5$ & - & $5 / 5$ & $4 / 5$ & $3 / 5$ & $4 / 5$ & - & $0 / 5$ & - \\
4 & $5 / 5$ & - & - & - & - & $5 / 5$ & $1 / 5$ & $0 / 5$ & $2 / 5$ \\
5 & $4 / 5$ & - & - & - & - & $5 / 5$ & $4 / 5$ & $1 / 5$ & $1 / 5$ \\
\hline
\end{tabular}

${ }^{a}$ Five faba bean (Fiord) plants were inoculated per time period. In each experiment (Exp.), for each time period, five additional faba bean plants were left uninoculated as controls but none ever became infected.

b Number of PSbMV-infected plants/total number inoculated; - = not tested. Sap extracted from PSbMV-infected leaf samples from each plant was left at room temperature in porcelain mortars for each incubation period, then resuspended in distilled water $(1: 1)$ and inoculated immediately onto test plants without an abrasive. Newly emerged leaf samples from all plants were tested individually by enzyme-linked immunosorbent assay (ELISA) for up to 28 days after inoculation by ELISA. plants infected between the two cultivars $(P=0.79)$. Symptoms in infected plants were leaf rolling, mosaic and chlorosis, and moderate plant stunting. These symptoms were visible approximately 15 days after rubbing. When a healthy pea plant was allowed to grow and intertwine with an infected pea plant and no rubbing occurred, there was no evidence of passive contact transmission of PSbMV. None of the control plants became infected.

Simulated wind-mediated contact transmission. In three of the four types of experiments using a fan to simulate windy conditions, PSbMV transmission occurred at varying levels. In experiments $1 \mathrm{~A}$ and $1 \mathrm{~B}$, where plants were blown for $2 \mathrm{~h}$, transmission occurred in 1 of 6 pots (both experiments) and 4 of 6 (1A) to 5 of 6 (1B) pots when plants were dusted with diatomaceous earth prior to blowing (thereby giving significantly higher values than the former at $P=0.02$; Table 3 ). No transmission occurred in experiments $2 \mathrm{~A}$ and $2 \mathrm{~B}$. In experiment $3 \mathrm{~A}$, where plants were blown for $1 \mathrm{~h}$, plants in 3 of 6 tubs became infected and, in experiment $4 \mathrm{~A}$, where plants were blown for $2 \mathrm{~h}, 1$ of 5 became infected. No plant-to-plant transmission occurred in experiments $3 \mathrm{~B}$ and $4 \mathrm{~B}$. Transmission rates were significantly higher $(P=0.008)$ in experiments undertaken under cooler glasshouse conditions $(1 \mathrm{~A}, 1 \mathrm{~B}$, and $3 \mathrm{~A})$ than experiments undertaken in warmer glasshouse conditions (2A, 2B, 3B, 4A, and 4B). In the experiments in which PSbMV transmission was detected, only one of the plants immediately adjacent to the infector plant ever became infected, except on two occasions. These occasions were (i) one of the 3 of 5 tubs with transmission in experiment $3 \mathrm{~A}$, in which both immediately adjacent plants became infected; and (ii) five of the combined 9 of 12 pots dusted with diatomaceous earth in which transmission occurred in experiments $1 \mathrm{~A}$ and $1 \mathrm{~B}$, in which both immediately adjacent plants also became infected. There was no evidence that pea cultivar (Kaspa or Twilight) affected transmission. Symptoms on plants infected by wind-mediated contact transmission were leaf rolling, mosaic and chlorosis, and moderate plant stunting (Fig. 2). These symptoms were visible approximately 21 days after the first blow. No passive contact transmission of PSbMV occurred in pots or tubs left unblown in any of the experiments and none of the control plants ever became infected.

The transformed OD $\left(\mathrm{A}_{405}\right)$ values for PSbMV titer in the pea infector plants from experiment $2 \mathrm{~B}$ had a significantly lower mean (1.14) than the transformed OD values from those in experiments $1 \mathrm{~A}$ and $1 \mathrm{~B}(1.59)(P<0.001)$.

\section{Discussion}

This study demonstrated that contact transmission of PSbMV can occur from infected to healthy field pea plants following leaf rubbing and simulated wind blowing. It also demonstrated that some PSbMV infectivity can survive in undiluted sap for at least $30 \mathrm{~h}$. This level of stability is a prerequisite for contact transmission to occur. The wounds created by leaf rubbing and simulated wind allowed contact transmission of PSbMV to take place. This suggests that contact transmission might play an important role in spread of PSbMV early

Table 2. Contact transmission of Pea seed-borne mosaic virus (PSbMV) by leaf rubbing onto leaves of pea plants ${ }^{\mathrm{a}}$

\begin{tabular}{|c|c|c|c|c|c|c|}
\hline \multirow[b]{2}{*}{ Exp. } & \multicolumn{3}{|c|}{ Twilight } & \multicolumn{3}{|c|}{ Kaspa } \\
\hline & Leaf rub & Passive & Control & Leaf rub & Passive & Control \\
\hline 1 & $2 / 10$ & $0 / 10$ & $0 / 10$ & $4 / 10$ & $0 / 10$ & $0 / 10$ \\
\hline 2 & $2 / 10$ & $0 / 10$ & $0 / 10$ & $3 / 10$ & $0 / 10$ & $0 / 10$ \\
\hline 3 & $2 / 10$ & $0 / 10$ & $0 / 10$ & $1 / 10$ & $0 / 10$ & $0 / 10$ \\
\hline 4 & $2 / 10$ & $0 / 10$ & $0 / 10$ & $1 / 10$ & $0 / 10$ & $0 / 10$ \\
\hline
\end{tabular}

a There were four experiments (Exp.) each with Twilight and Kaspa pea, each with 10 plants per treatment. Newly emerged leaf samples from all plants were tested by enzyme-linked immunosorbent assay individually for up to 28 days after rubbing. Shown are number of PSbMV-infected plants/total number of plants. Leaf rub $=$ a leaf from a separate PSbMV-infected pea plant was rubbed onto the leaf surface of the top five to six leaves of the healthy pea plant. Passive = healthy and PSbMV-infected field pea plants were allowed to intertwine naturally for 27 days to test for any passive transmission. 
in the life of a pea crop by expanding infection foci before aphid arrival. As mentioned above, prior to this study, only anecdotal evidence existed of possible PSbMV spread occurring in the absence of aphids (Coutts et al. 2009). This research also found that PSbMV spread assisted by simulated wind was favored by (i) cooler temperatures, presumably reflecting adaptation of this virus to cool conditions, and (ii) presence of abrasive, suggesting a possible role for airborne dust and sand in increasing abrasion, thereby enhancing wind-mediated spread.

Our findings regarding PSbMV stability in sap support previous findings by Knesek et al. (1974) on its survival in diluted sap, which did not specify whether an abrasive was used for inoculation. We found that infective sap retained high levels of infectivity after $6 \mathrm{~h}$ and lower levels still remained after $30 \mathrm{~h}$ of incubation. This resembles previous findings with PVY and ZYMV, which remained infective in sap for at least $24 \mathrm{~h}$ (Coutts and Jones 2015; Coutts et al. 2013). As in these recent studies, by not using water during sap extraction and not using abrasive or buffer for inoculation, we attempted to reproduce a situation that resembled a field scenario. This was not done in earlier stability studies (Broadbent and Fletcher 1963; Knesek et al. 1974; Wright 1974). Our findings indicate that PSbMV would be likely to retain infectivity on contaminated equipment such as tools, clothes, boots, and machinery tires used in production of garden and vining pea crops. This is less likely to be an issue in field pea production because machinery use is much more limited and there is no manual handling. Further research with garden and vining pea plants would be needed to explore this possibility.

No passive transmission of PSbMV occurred by intertwining of infected and healthy plants during this study, showing that contact

Table 3. Simulated wind-mediated contact transmission of Pea seed-borne mosaic virus (PSbMV) to field pea plants

\begin{tabular}{|c|c|c|c|c|}
\hline \multirow[b]{2}{*}{ Exp. ${ }^{c}$} & \multicolumn{2}{|c|}{ Treatment $^{\mathbf{a}}$} & \multicolumn{2}{|c|}{ Duplicate $^{b}$} \\
\hline & Infector & Wind (h) & $\mathbf{A}$ & B \\
\hline \multirow[t]{4}{*}{1} & $+(\mathrm{P})$ & 2 & $1 / 6$ & $1 / 6$ \\
\hline & - & 2 & $0 / 6$ & $0 / 6$ \\
\hline & $+(\mathrm{P})$ & - & $0 / 6$ & $0 / 6$ \\
\hline & $+(\mathrm{P})$ & $2(+\mathrm{DE})$ & $4 / 6$ & $5 / 6$ \\
\hline \multirow[t]{4}{*}{2} & $+(\mathrm{P})$ & 2 & $0 / 6$ & $0 / 6$ \\
\hline & - & 2 & $0 / 6$ & $0 / 6$ \\
\hline & $+(\mathrm{FB})$ & 2 & $0 / 6$ & $0 / 6$ \\
\hline & $+(\mathrm{FB})$ & - & $0 / 6$ & $0 / 6$ \\
\hline \multirow[t]{3}{*}{3} & $+(\mathrm{P})$ & 1 & $3 / 6$ & $0 / 6$ \\
\hline & - & 1 & $0 / 6$ & $0 / 6$ \\
\hline & $+(\mathrm{P})$ & - & $0 / 6$ & $0 / 6$ \\
\hline \multirow[t]{3}{*}{4} & $+(\mathrm{P})$ & 2 & $1 / 5$ & $0 / 5$ \\
\hline & - & 2 & $0 / 5$ & $0 / 5$ \\
\hline & $+(\mathrm{P})$ & - & $0 / 5$ & $0 / 5$ \\
\hline
\end{tabular}

a Infector $=$ PSbMV isolate $\mathrm{W} 1$ infector plant, $\mathrm{P}=$ field pea, $\mathrm{FB}=$ faba bean, $\mathrm{DE}=$ diatomaceous earth, and Wind = wind duration.

b Number of PSbMV-infected/total number of pots or tubs. Experiments (Exp.) 1A, 1B, and 3A were undertaken under cooler glasshouse conditions, and the others under warmer conditions.

c Each experiment was duplicated (A and B). Exp. 1 consisted of pots each containing two healthy Kaspa field pea plants. Single infector plants of Kaspa were transplanted in between them. There were three treatments depending on presence $(+)$ or absence $(-)$ of an infector plant and the occurrence of blowing (= simulated wind), with six pots per treatment. An additional treatment was included in which plants were dusted with diatomaceous earth prior to blowing. Exp. 2 was similar but the diatomaceous earth treatment was excluded and consisted of pots each containing two healthy Twilight field pea plants. A single infector plant of Twilight or Fiord faba bean was transplanted in between them. Exp. 3 and 4 consisted of tubs each containing a row of healthy Twilight field pea plants. Single infector plants of Twilight were transplanted into the middle of each row. There were six tubs (Exp. 3) or five tubs (Exp. 4) per treatment. A newly emerged leaf was sampled from each plant and tested by ELISA 21, 28, and 35 days after the first blowing. transmission cannot occur without an external force to cause friction and wounding, which is a prerequisite for such transmission to occur (Bawden 1964; Matthews 1981). When an infected pea leaf was rubbed manually onto leaves from a healthy pea plant, transmission occurred in 1 of 10 to 4 of 10 plants. When pots or tubs containing an infector plant and 2 to 10 healthy plants were blown with a fan, over the four duplicated types of experiments, occurrence of simulated wind-mediated contact transmission was favored by cool conditions. Transmission occurred consistently when the glasshouse was at cooler temperatures $\left(14\right.$ to $\left.20^{\circ} \mathrm{C}\right)$ but only once when it was at warmer temperatures $\left(20\right.$ to $\left.30^{\circ} \mathrm{C}\right)$. The most likely explanation for this is that PSbMV was at a higher titer in infector plant leaves in the cooler conditions than the warmer conditions. This explanation is supported by the significantly higher OD values generated by leaf samples of infector pea plants under cooler conditions. It is unlikely that drying of sap during the rubbing process created by wind from fans would have reduced transmission under warmer conditions because transmission would have been instantaneous and the glasshouse conditions under which the experiments were done were kept equally humid at both times of the year. Moreover, when plants were dusted with diatomaceous earth prior to blowing, contact transmission of PSbMV was enhanced, indicating that airborne dust and sand particles might play a role in accentuating wounding and, thus, increase contact transmission under field conditions.

Simulated wind-mediated contact transmission occurred in this study despite field pea leaves being small, lacking abrasive hairs, and having interlocking tendrils which decrease motion within rows due to the firmer connections between plants (Holland et al. 1991). Pea leaves are smooth, with a small surface area, indicating that the force exerted by wind would need to be significant to initiate wounding for contact transmission of PSbMV to occur. In our experiments, PSbMV transmission occurred early, when plants were younger, which was before extensive tendril interlocking. In older plants, this interlocking seems likely to diminish wind-mediated contact transmission in the field. Further research with conventionalleafed field pea cultivars (i.e., nonsemileafless) is needed to determine whether their fewer tendrils would permit spread to continue in

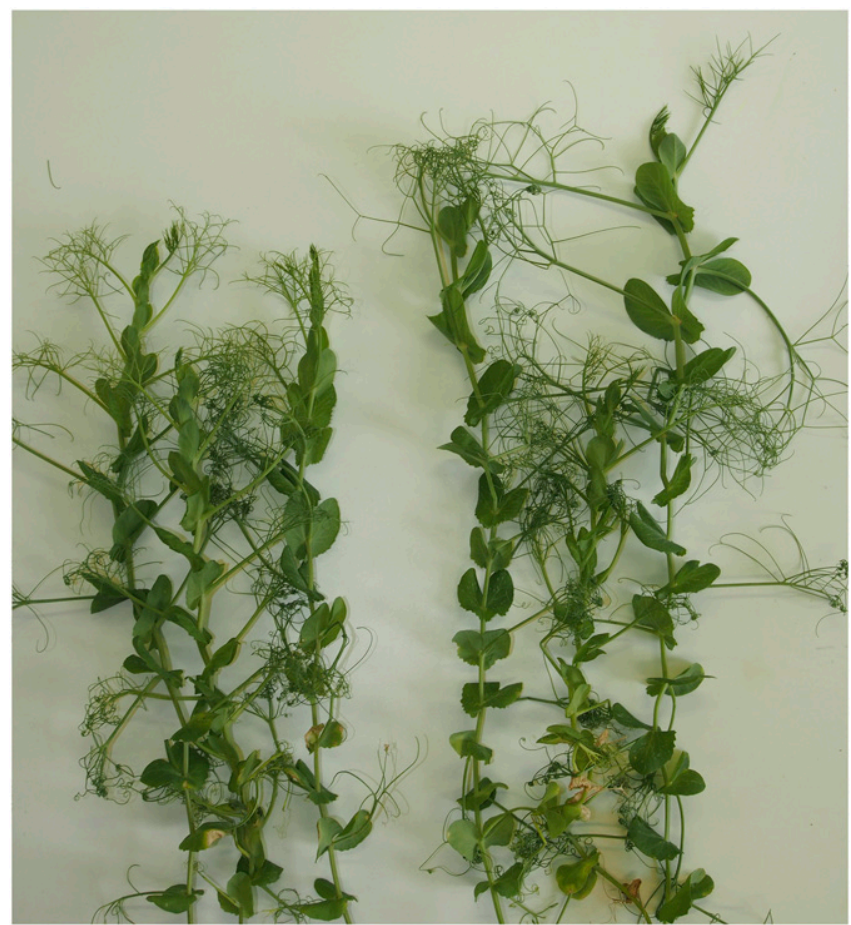

Fig. 2. Pea seed-borne mosaic virus transmission from a central infector plant to neighboring healthy plants when blown with a fan (left) compared with no transmission when not blown with a fan (right) (experiment 1B). Infected plants show stunting, chlorosis, and leaf distortion. 
older plants. Such cultivars have larger leaves which could also favor transmission by wind because of a greater surface area for contact between leaves of neighboring plants. The same applies to garden and vining pea production in which conventionalleafed cultivars are used.

There is likely to be little difference in PSbMV susceptibility to contact transmission between pea cultivars because its ability to be mechanically inoculated is uniform over a wide range of cultivars (Aapola et al. 1974). Also, our leaf-rubbing data showed no significant differences in susceptibility between Kaspa and Twilight. The PSbMV isolate we used, W1, belongs to pathotype P-2, which is a prominent pathotype in Australia (Wylie et al. 2011). It would be worthwhile to determine whether different PSbMV pathotypes vary in their contact transmissibility. Furthermore, young plants in the field are succulent and, therefore, still vulnerable to contact transmission (Bawden 1964). Field experiments using aphid-proof nets and higherpowered fans with intermittent action to simulate gusty winds could be used to investigate PSbMV contact transmission outside the glasshouse. Plots of pea plants containing known infection sources monitored over the length of a growing season would be needed for this.

In the field, contact transmission between initial seed-infected and healthy pea plants would increase the inoculum source for PSbMV acquisition by aphids by expanding infection foci prior to aphid arrival during the critical early phase of the epidemic shortly after germination, thereby accelerating PSbMV spread. Spread could also occur soon after aphid arrival from plants infected by contact or aphid PSbMV transmission to neighboring healthy plants, further expanding infection foci for aphids to acquire and spread the virus. If conditions are favorable for aphid build-up, a higher final PSbMV incidence would then occur, resulting in increased yield and seed quality losses (Coutts et al. 2009). Management practices that minimize PSbMV contact transmission would be likely to help reduce the overall PSbMV spread in a field pea crop by minimizing expansion of infection foci from seed-infected plants prior to aphid arrival. Lower sowing rates would result in a lower plant density, in turn resulting in less contact between plants in the critical early phase of the growing season. However, by analogy with lupin studies with Cucumber mosaic virus, a lower plant density would also favor increased aphid landings due to the presence of bare earth between plants before canopy closure (Jones 2001, references therein). Therefore, in the presence of high aphid numbers prior to canopy closure, this would probably outweigh any benefit from sowing at lower seeding rates. Exploiting natural windbreaks such as remnant bushland to shelter a pea crop would provide a simple way to minimize windmediated contact transmission of PSbMV. Use of artificial wind breaks would be effective in intensive garden or vining pea production but not feasible in broadacre field pea production.

In conclusion, the information provided by this study is important to enable accurate modeling of the PSbMV-field pea pathosystem to predict PSbMV epidemics and support development of a decision support system allowing more appropriate and efficient use of management practices (Congdon et al. 2014). Additionally, this study and the studies done previously by Coutts et al. (2013) and Coutts and Jones (2015) highlight the importance of undertaking research into contact transmission of additional potyviruses which infect other crops.

\section{Acknowledgments}

We thank E. Gajda and M. Banovic for assisting with ELISA testing of samples. This research was funded by The Australian Research Council Linkage Project (LP120200224), The University of Western Australia, and the Department of Agriculture and Food Western Australia (DAFWA). The experiments were undertaken using the glasshouse and laboratory facilities of DAFWA.

\section{Literature Cited}

Aapola, A. A., Knesek, J. E., and Mink, G. I. 1974. The influence of inoculation procedure on the host range of pea-seed-borne mosaic virus. Phytopathology 64:1003-1006

Ali, A., and Randles, J. W. 1998. The effects of two pathotypes of pea seed-borne mosaic virus on the morphology and yield of pea. Australas. Plant Pathol. 27: 226-233.

Bawden, F. C. 1964. Plant Viruses and Virus Diseases. The Ronald Press Company, New York.
Bos, L., Hampton, R. O., and Makkouk, K. M. 1988. Viruses and virus diseases of pea, lentil, faba bean and chickpea. Pages 591-615 in: World Crops: Cool Season Food Legumes, Vol. 5. R. J. Summerfield, ed. Kluwer Academic Publishers, Dordecht, The Netherlands.

Brey, C. W., Johnson, G. D., and Blodgett, S. L. 1988. Survey of Montana grasses for wheat curl mite (Acari: Eriophyidae), the vector of wheat streak mosaic virus. J. Agric. Ent. 15:173-181.

Brierly, P. 1962. Transmission of some gladiolus viruses on tools in harvesting flowers and corms. Plant Dis. Rep. 46:505.

Broadbent, L., and Fletcher, J. T. 1963. The epidemiology of tomato mosaic IV Persistence of virus on clothing and glasshouse structures. Ann. Appl. Biol. 52:233-241.

Clark, M. F., and Adams, A. N. 1977. Characteristics of the microplate method of enzyme-linked immunosorbent assay for the detection of plant viruses. J. Gen. Virol. 34:475-483.

Cleugh, H. A., Miller, J. M., and Böhm, M. 1998. Direct mechanical effects of wind on crops. Agrofor. Syst. 41:85-112.

Congdon, B. S., Renton, M., Coutts, B. A., Van Leur, J. A. G., and Jones, R. A. C. 2014. Understanding, managing and forecasting Pea seed-borne mosaic virus in field pea. (Abstr.) Page 34 in: 11th Australas. Plant Virol. Workshop, Brisbane, Australia

Coutts, B. A., and Jones, R. A. C. 2015. Potato virus Y: Contact transmission, stability, inactivation and infection sources. Plant Dis. 99:387-394.

Coutts, B. A., Kehoe, M. A., and Jones, R. A. C. 2013. Zucchini yellow mosaic virus: Contact transmission, stability on surfaces, and inactivation with disinfectants. Plant Dis. 97:765-771

Coutts, B. A., Prince, R. T., and Jones, R. A. C. 2008. Further studies on Pea seedborne mosaic virus in cool-season crop legumes: Responses to infection and seed quality defects. Aust. J. Agric. Res. 59:1130-1145.

Coutts, B. A., Prince, R. T., and Jones, R. A. C. 2009. Quantifying effects of seedborne inoculum on virus spread, yield losses, and seed infection in the Pea seed-borne mosaic virus-field pea pathosystem. Phytopathology 99:11561167.

Fletcher, J. D. 1993. Surveys of virus diseases in pea, lentil, dwarf and broad bean crops in South Island, New Zealand. N. Z. J. Crop Hortic. Sci. 21:45-52.

Franc, G. D., and Bantarri, E. E. 2001. Transmission of viruses. Pages 159-175 in: Viruses and Virus-Like Diseases of Potatoes and Production of Seed-Potatoes. G. Loebenstein, P. H. Berger, A. A. Brunt, and R. H. Lawson, eds. Kluwer Academic Publishers, Dordrecht, The Netherlands.

Hampton, R. O., and Mink, G. I. 1975. Pea Seed-borne Mosaic Virus. CMI/AAB, Descriptions of Plant Viruses Kew, Surrey, England.

Holland, M. R., Grace, J., and Hedley, C. L. 1991. Momentum absorption by driedpea crops. I. Field measurements over and within varieties of differing leaf structure. Agric. For. Meteorol. 54:67-79.

Hu, J. S., Ferreira, S., Xu, M. Q., Lu, M., Iha, M., Pflum, E., and Wang, M. 1994 Transmission, movement and inactivation of cymbidium mosaic and odontoglossum ringspot viruses. Plant Dis. 78:633-636.

Jensen, D. D., and Gold, A. H. 1955. Hosts, transmission and electron microscopy of cymbidium mosaic virus with special reference to cattleya leaf necrosis. Phytopathology 45:327-334.

Jones, R. A. C. 2001. Developing integrated disease management strategies against non-persistently aphid-borne viruses: A model programme. Integr. Pest Manage. Rev. 6:15-46.

Kamenova, I., and Adkins, S. 2004. Transmission, in planta distribution and management of Hibiscus latent Fort Pierce virus, a novel tobamovirus isolated from Florida hibiscus. Plant Dis. 88:674-679.

Khetarpal, R. K., and Maury, Y. 1987. Pea seed-borne mosaic virus: A review. Agronomie 7:215-224.

Knesek, J. E., Mink, G. I., and Hampton, R. O. 1974. Purification and properties of pea seed-borne mosaic virus. Phytopathology 64:1076-1081.

Latham, L. J., and Jones, R. A. C. 2001a. Incidence of virus infection in experimental plots, commercial crops, and seed stocks of cool season crop legumes. Aust. J. Agric. Res. 52:397-413.

Latham, L. J., and Jones, R. A. C. 2001b. Alfalfa mosaic and Pea seed-borne mosaic viruses in cool season crop, annual pasture, and forage legumes: Susceptibility, sensitivity, and seed transmission. Aust. J. Agric. Res. 52: 771-790.

Loughnane, J. B., and Murphy, P. A. 1938. Dissemination of potato virus X and F by leaf contact. Sci. Proc. R. Dublin Soc. 22:1-15.

Makkouk, K. M., Kumari, S. G., van Leur, J. A., and Jones, R. A. 2014. Control of plant virus diseases in cool-season grain legume crops. Adv. Virus Res. 90: 207-253.

Matthews, R. E. F. 1981. Plant Virology, 2nd ed. Academic Press, New York.

McKirdy, S. J., Jones, R. A. C., and Sivasithamparam, K. 1998. Determining the effectiveness of grazing and trampling by livestock in transmitting white clover mosaic and subterranean clover mottle viruses. Ann. Appl. Biol. 132:91-105.

Sarra, S., Oevering, P., Guindo, S., and Peters, D. 2004. Wind-mediated spread of Rice yellow mottle virus (RYMV) in irrigated rice crops. Plant Pathol. 53: 148-153.

Sill, W. J. J. 1953. Wind and blowing factors in the spread of wheat streak mosaic virus. (Abstr.) Phytopathology 43:484

Todd, J. M. 1958. Spread of potato virus X over a distance. Pages 132-141 in: Proc. 3rd Conf. Potato Virus Dis. Lisse, Wageningen, The Netherlands. 
Wilson, C. R., and Jones, R. A. C. 1993. Resistance to potato leafroll virus infection and accumulation in potato cultivars, and the effects of previous infection with other viruses on expression of resistance. Aust. J. Agric. Res. 44:1891-1904.

Wintermantel, W. M. 2011. A comparison of disinfectants to prevent spread of potyviruses in greenhouse tomato production. Online publication. Plant Health Prog. doi:10.1094/PHP-2011-0221-01-RS
Wright, N. S. 1974. Retention of infectious potato virus X on common surfaces. Am. Potato J. 51:251-253.

Wylie, S. J., Coutts, B. A., and Jones, R. A. C. 2011. Genetic variability of the coat protein sequence of Pea seed-borne mosaic virus isolates and the current relationship between phylogenetic placement and resistance groups. Arch. Virol. 156:1287-1290. 